\title{
Calculation of the solid solubilities in supercritical carbon dioxide using a modified mixing model
}

\author{
Cheng-Chia Huang, Muoi Tang ${ }^{1}$, Wei-Han Tao ${ }^{1}$, Yan-Ping Chen* \\ Department of Chemical Engineering, National Taiwan University, Taipei, Taiwan, ROC
}

Received 25 September 2000; accepted 2 October 2000

\begin{abstract}
The Peng-Robinson equation of state and a modified Huron-Vidal type mixing model with a volume correction term are applied in this study to calculate the solid solubilities of aromatic, fatty acid and heavy alcohol compounds in supercritical carbon dioxide. The UNIFAC activity coefficient model with its optimally fitted binary interaction parameters is used in this study. A volume correction term is employed, and its parameters are correlated as functions of the solid molar volume for both non-polar and polar systems. The effect of the sublimation vapor pressure on the calculation of solid solubilities in supercritical carbon dioxide is examined. The sublimation vapor pressures for heavy compounds are fitted in this study to yield the optimally calculated results of the solid solubility. Reasonable sublimation vapor pressures are obtained and their values are well correlated by the Antoine equation. A generalized calculation model is proposed in this study which gives satisfactory results of the solid solubility in supercritical carbon dioxide for both the binary and ternary systems. (C) 2001 Elsevier Science B.V. All rights reserved.
\end{abstract}

Keywords: Equation of state; Group contribution method; Mixing rules; Solid solubilities; Supercritical carbon dioxide

\section{Introduction}

Supercritical fluids (SCF) are widely applied in extraction, reaction, separation and crystal growth processes. The key point for the design of process equipment and selection of operating condition is the equilibrium solubility data. Only a few solid solubility data were reported in literature [1]. The accurate measurement of the solid solubility in supercritical fluid is also difficult and time consuming. For the purpose of a wider range of application, a suitable thermodynamic model should be used to correlate and predict the equilibrium solubility data required in those related fields [2]. Thermodynamic models that employ equations of state (EOS) and mixing rules for the calculation of solubilities of solids in supercritical fluids have been presented by many investigators [3-7]. The traditional van der Waals (VDW) mixing rules

\footnotetext{
* Corresponding author. Tel.: +886-2363-5230; fax: +886-2362-3040.

E-mail address: ypchen@ccms.ntu.edu.tw (Y.-P. Chen).

${ }^{1}$ Present address: Department of Chemical Engineering, Chinese Culture University, Taipei, Taiwan, ROC.
} 
are usually employed with optimally fitted binary interaction parameters. Unfortunately, those parameters cannot be well correlated as functions of temperature or pressure, especially for systems involving heavy or complex compounds [8]. On the other hand, empirical models can be used for the calculations of solid solubilities. Since the parameters in the empirical models are usually not generalized, it is difficult to apply them for predictive or multi-component computations.

A modified Huron-Vidal [9] type mixing model with a volume correction term has been proposed for calculating the solid solubilities in supercritical carbon dioxide [10]. Solubilities of five aromatic compounds in supercritical carbon dioxide were calculated by that modified model using the Patel-Teja EOS [11]. The mixture energy parameter of the EOS was determined by using a UNIFAC group contribution method. The volume correction term has been well correlated as a function of the solid molar volume. Further investigations [12-14] also applied this modified model to calculate the solubilities of steroids, polar and non-polar aromatic compounds and solid mixtures in supercritical fluids. In the previous studies, the range of the solid molar volume for the volume correction term was less than $0.18 \mathrm{l} / \mathrm{mol}$. This EOS + UNIFAC method with a volume correction term gives good accuracy in correlating and predicting the solid solubility in supercritical carbon dioxide, as also stated by Zhong and Masuoka [15]. The range of solid molar volume in the volume correction term can further be improved to include solid solute of heavier components.

There are many properties that affect the calculation results of solid solubilities in supercritical fluid by using EOS and mixing rules. Besides the critical constants, the sublimation vapor pressures of solids also play a dominant role to the calculation results [2]. The sublimation vapor pressure of high molecular weight compound is too small for accurate experimental measurement. Reverchon et al. [16] suggested that the sublimation vapor pressure should be considered as an adjustable parameter.

In this work, solid solubility calculations with a modified mixing model are extended to fatty acid and heavy alcohol compounds where the solid molar volumes range from 0.2 to $0.35 \mathrm{l} / \mathrm{mol}$. Improved generalized correlation equations for the volume correction parameters are presented. Optimally fitted sublimation vapor pressures of various solids are presented. Although these solid vapor pressures are obtained by fitting the solid solubility, their values are reasonable in comparison to some available experimental data of aromatic compounds. Calculation results of the solid solubility and the comparison with those from the VDW mixing rules and the best-fitted binary parameters are also demonstrated.

\section{Calculation of the solid solubility}

The solubility of a solid (component 2) in supercritical carbon dioxide (component 1) is

$$
y_{2}=\frac{P_{2}^{\mathrm{sub}} \exp \left(V_{\mathrm{s}}\left(P-P_{2}^{\mathrm{sub}}\right) / R T\right)}{\hat{\phi}_{2}^{\mathrm{SCF}} P}
$$

where $P_{2}^{\text {sub }}$ is the sublimation vapor pressure of the solid, $V_{\mathrm{s}}$ is the solid molar volume, $\hat{\phi}_{2}^{\text {scf }}$ is the fugacity coefficient of the solid in the supercritical phase. The fugacity coefficient of the solid is calculated by the Peng-Robinson EOS [17] in this study:

$$
P=\frac{R T}{V-b}-\frac{a}{V^{2}+2 b V-b^{2}}
$$


where $a$ and $b$ are the EOS energy and volume parameters which are determined from the characteristic critical constants and acentric factors for pure fluids. Various mixing rules can be applied to calculate the mixture EOS parameters. The simple VDW type mixing model determines the mixture EOS parameters by considering the mixture as a pseudopure component:

$$
\begin{aligned}
a_{m} & =\sum_{i} \sum_{j} x_{i} x_{j}\left(a_{i} a_{j}\right)^{0.5}\left(1-k_{i j}\right) \\
b_{m} & =\sum_{i} \sum_{j} x_{i} x_{j} \frac{1}{2}\left(b_{i}+b_{j}\right)\left(1-l_{i j}\right)
\end{aligned}
$$

where $k_{i j}$ and $l_{i j}$ are the adjustable binary interaction parameters that are obtained from regression of the experimental solubility data. These empirical parameters are usually temperature-dependent and cannot be correlated in a systematic form.

Huron and Vidal [9] proposed an improved predictive method to obtain the EOS mixture parameters. At an infinite pressure limit, the excess Gibbs free energy calculated from the EOS is set equal to that from a group contribution activity coefficient model. This approach has been employed to calculate the phase equilibria of non-ideal mixtures by many investigators. For example, Sheng et al. [10] applied this method and Patel-Teja EOS to determine the solid solubility in supercritical carbon dioxide. They also replaced the Gibbs free energy in the original Huron-Vidal model by the Helmholtz free energy. A volume correction term was proposed by Sheng et al. [10] to evaluate the volume parameter of a fluid mixture. Chen et al. [14] employed the modified equation of Sheng et al. [10] and applied the Peng-Robinson EOS in calculating the solubilities of solids and solid mixtures. The excess Helmholtz free energy calculated from the Peng-Robinson EOS at an infinite pressure limit is expressed as

$$
\left(\frac{A^{\mathrm{E}}}{R T}\right)_{P=\infty}=\frac{\ln (3-2 \sqrt{2})}{2 \sqrt{2} R T}\left(\frac{a_{m}}{b_{m}}-\sum_{i} \frac{x_{i} a_{i}}{b_{i}}\right)
$$

The energy parameter of a mixture is then calculated by

$$
a_{m}=2 \sqrt{2} b_{m}\left(\sum_{i} x_{i} \frac{a_{i}}{2 \sqrt{2} b_{i}}-\frac{A^{\mathrm{E}}}{\ln (3+2 \sqrt{2})}\right)
$$

The volume parameter of a mixture is calculated by the direct summation of the pure component properties and a volume correction term, $b^{\mathrm{E}}$ :

$$
b_{m}=\sum_{i} x_{i} b_{i}+b^{\mathrm{E}}
$$

the volume correction term is expressed by a simple Margules type equation:

$$
b^{\mathrm{E}}=x_{1} x_{2}\left(K_{1} x_{1}+K_{2} x_{2}\right)
$$

where $K_{1}$ and $K_{2}$ are two temperature-independent constants for each binary system.

Using the above mixing rules, the fugacity coefficient of a solid component calculated from the Peng-Robinson EOS in the supercritical phase is expressed as 


$$
\begin{aligned}
\ln \hat{\phi}_{i}^{\mathrm{scf}}= & -\ln \left(Z_{m}-B_{m}\right)+\frac{\hat{b}_{i}}{V_{m}-b_{m}}-\left[\left(\frac{a_{i}}{2 \sqrt{2} R T b_{i}}\right)+\frac{\ln \gamma_{i}}{\ln (3-2 \sqrt{2})}\right] \ln \left(\frac{Q_{v}+\sqrt{2} b_{m}}{Q_{v}-\sqrt{2} b_{m}}\right) \\
& +\frac{a_{m} \hat{b}_{i}}{R T\left(Q_{v}^{2}-2 b_{m}^{2}\right)}-\frac{2 a_{m} Q_{v} \hat{b}_{i} b_{m}}{2 R T b_{m}^{2}\left(Q_{v}^{2}-2 b_{m}^{2}\right)}
\end{aligned}
$$

where

$$
\begin{aligned}
Z_{m} & =\frac{P V_{m}}{R T} \\
B_{m} & =\frac{P b_{m}}{R T} \\
\hat{b}_{i} & =\left(\frac{\partial n b_{m}}{\partial n_{i}}\right)_{T, V, n_{j \neq i}} \\
Q_{v} & =V_{m}+b_{m}
\end{aligned}
$$

In this study, the group contribution UNIFAC model [18] with a modified combinatorial part [10] is used to calculate the activity coefficient. Most group interaction parameters were taken from Larsen et al. [18]. The group interaction parameters of the residual part including $\mathrm{CO}_{2}, \mathrm{NAC}, \mathrm{ACH}, \mathrm{CH}_{2}, \mathrm{ACCH}_{2}$, $\mathrm{OH}, \mathrm{ACOH}$, and $\mathrm{COOH}$ functional groups have been regressed from VLE or gas solubilities data by Chen et al. [12-14]. The group interaction parameter is written in a temperature dependent form as

$$
a_{m n}=a_{m n, 1}+a_{m n, 2}\left(T-T_{0}\right)+a_{m n, 3}\left(T \ln \frac{T_{0}}{T}+T-T_{0}\right)
$$

where the reference temperature $T_{0}$ is $298.15 \mathrm{~K}$, and $a_{m n, i}(i=1$ to 3$)$ are parameters for each functional pair.

The modified combinatorial contribution of the UNIFAC model suggested by Sheng et al. [10] is used in this study for calculating the energy parameter of the EOS:

$$
\frac{G^{\mathrm{E}}}{R T}=\sum_{i} x_{i} \ln \left(\frac{\psi_{i}^{0}}{x_{i}}\right)-\frac{z}{2} \sum_{i} q_{i} x_{i} \ln \left(\frac{\psi_{i}}{\theta_{i}}\right)
$$

where

$$
\begin{aligned}
\psi_{i}^{0} & =\frac{x_{i}\left(r_{i}\right)^{p_{i}}}{\sum_{j} x_{j}\left(r_{j}\right)^{p_{j}}} \\
\psi_{i} & =\frac{x_{i} r_{i}}{\sum_{j} x_{j} r_{j}} \\
p_{i} & =1-\frac{1}{0.8\left(q_{i} r_{i}^{-2 / 3}-1\right)^{1.5}+1} \\
\theta_{i} & =\frac{x_{i} q_{i}}{\sum_{j} x_{j} q_{j}}
\end{aligned}
$$

where $r_{i}$ and $q_{i}$ are the group volume and surface area parameters of the UNIFAC model. 
Table 1

Binary group interaction parameters of the UNIFAC model ${ }^{\mathrm{a}}$

\begin{tabular}{|c|c|c|c|c|c|c|c|}
\hline Group pair $(m-n)$ & $a_{m n, 1}$ & $a_{m n, 2}$ & $a_{m n, 3}$ & $a_{n m, 1}$ & $a_{n m, 2}$ & $a_{n m, 3}$ & Reference \\
\hline $\mathrm{CO}_{2}-\mathrm{ACH}$ & 129.3 & -0.347 & -1.914 & 4.162 & 0.288 & -0.358 & {$[10]$} \\
\hline $\mathrm{CO}_{2}-\mathrm{NAC}$ & 455.6 & -2.317 & -3.065 & 1304 & 0.256 & 0.150 & {$[10]$} \\
\hline ACH-NAC & 372.2 & 1.340 & 1.486 & 1.959 & 1.126 & 1.142 & {$[10]$} \\
\hline $\mathrm{CO}_{2}-\mathrm{CH}_{2}$ & 467.2 & 6.551 & 10.88 & -2.825 & -2.719 & -4.085 & [10] \\
\hline $\mathrm{CO}_{2}-\mathrm{ACCH}_{2}$ & 388.5 & -0.480 & 1.367 & -112.2 & -0.867 & -0.407 & [10] \\
\hline $\mathrm{ACH}-\mathrm{ACCH}_{2}$ & 167.0 & 0 & 0 & -146.8 & 0 & 0 & {$[10]$} \\
\hline $\mathrm{NAC}-\mathrm{ACCH}_{2}$ & 582.6 & 0.829 & 0.634 & 697.6 & 0.542 & 0.657 & {$[10]$} \\
\hline $\mathrm{CO}_{2}-\mathrm{ACOH}$ & 882.03 & -0.030 & 0.510 & 494.93 & -3.120 & 0.670 & [14] \\
\hline $\mathrm{ACH}-\mathrm{ACOH}$ & 1304.34 & -1.530 & 0 & 835.75 & 0.100 & 0 & {$[14]$} \\
\hline $\mathrm{NAC}-\mathrm{ACOH}$ & 28.50 & 0.190 & -0.190 & 648.03 & -0.550 & -0.010 & {$[14]$} \\
\hline $\mathrm{ACCH}_{2}-\mathrm{ACOH}$ & 884.9 & 0 & 0 & 244.2 & 0 & 0 & {$[14]$} \\
\hline $\mathrm{CO}_{2}-\mathrm{OH}$ & 206.54 & 0.8593 & -22.62 & 240.24 & 3.2069 & -9.930 & [12] \\
\hline $\mathrm{CH}_{2}-\mathrm{OH}$ & 972.8 & 0.2687 & 8.773 & 637.5 & -5.832 & -0.8703 & [12] \\
\hline $\mathrm{CO}_{2}-\mathrm{COOH}$ & -1167.3 & -11.562 & -0.475 & 120.37 & 0.145 & 1.291 & [12] \\
\hline $\mathrm{CH}_{2}-\mathrm{COOH}$ & 664.1 & 1.317 & -4.904 & 171.5 & -1.463 & 0.6759 & {$[18]$} \\
\hline $\mathrm{ACH}-\mathrm{COOH}$ & 537.4 & 0 & 0 & 62.32 & 0 & 0 & {$[18]$} \\
\hline $\mathrm{ACCH}_{2}-\mathrm{COOH}$ & 317.9 & 10.31 & 0 & 460.8 & -4.412 & 0 & [19] \\
\hline
\end{tabular}

a ACH: aromatic $\mathrm{CH}$; NAC: naphthalene carbon; $\mathrm{ACCH}_{2}$ : aromatic $\mathrm{CH}_{2} ; \mathrm{ACOH}$ : aromatic $\mathrm{OH}$.

\section{Results and discussion}

The group contribution UNIFAC activity coefficient model is employed in this study to determine the EOS energy parameter of the mixture. The group interaction parameters of the UNIFAC model are provided by previous investigators $[10,12,14,18,19]$ from vapor-liquid equilibrium calculations using either the Patel-Teja or the Peng-Robinson EOS. Table 1 shows those binary group interaction parameters that are also used in this study.

In this study, we calculate the solubilities of aromatic and heavy alcohol and acid compounds in supercritical carbon dioxide. The critical constants, acentric factors and solid molar volumes of these compounds are taken from literature and are listed in Table 2. Two major contributions are presented in this work. First, the solid sublimation vapor pressures, as well as the volume correction term, are simultaneously taken as adjustable parameters in the solid solubility calculations. Their optimally fitted values are determined by minimizing the following objective function of the calculated errors of the solid solubilities in supercritical carbon dioxide for binary mixtures:

$$
\mathrm{obj}=\sum\left[\frac{\left(y_{2}^{\mathrm{cal}}-y_{2}^{\exp }\right)}{y_{2}^{\exp }}\right]^{2}
$$

The optimally fitted solid vapor pressures are then correlated in this study by the Antoine type equation for various compounds. Second, the volume correction term is correlated in a wider range of solid molar volumes for both non-polar and polar solids.

Fig. 1 shows the solid sublimation vapor pressure of anthracene from different literature sources. It is demonstrated that the solid vapor pressures are lower than $10^{-5}$ bar where some uncertainty may exist in experimental measurements. In such conditions, it is practical to treat the solid vapor pressures as 
Table 2

Physical properties of solid compounds used in this study

\begin{tabular}{|c|c|c|c|c|}
\hline Compound & $T_{\mathrm{C}}(\mathrm{K})$ & $P_{\mathrm{C}}(\mathrm{atm})$ & $\omega$ & $V_{\mathrm{s}}(\mathrm{l} / \mathrm{mol})$ \\
\hline Naphthalene & $748.4[20]$ & $40.1[20]$ & $0.302[20]$ & $0.1100[4]$ \\
\hline Phenanthracene & $890.0[8]$ & $32.5[8]$ & $0.429[8]$ & $0.1530[20]$ \\
\hline Anthracene & $869.3[8]$ & $34.4[8]$ & $0.532[8]$ & $0.1426[21]$ \\
\hline 2,3-Dimethylnaphthalene & $785.0[8]$ & $31.8[8]$ & $0.424[8]$ & $0.1547[21]$ \\
\hline 2,6-Dimethylnaphthalene & $777.0[8]$ & $31.8[8]$ & $0.420[8]$ & $0.1392[21]$ \\
\hline Hexamethylbenzene & $758.0[6]$ & $24.1[6]$ & $0.515[6]$ & $0.1527[21]$ \\
\hline Pyrene & $936.0[20]$ & $25.7[20]$ & $0.509[20]$ & $0.1585[21]$ \\
\hline Fluorene & $826.4[6]$ & $29.5[6]$ & $0.406[6]$ & $0.1393[21]$ \\
\hline Triphenylene & $1013.6[22]$ & $28.9[22]$ & $0.492[22]$ & $0.1750[23]$ \\
\hline Chrysene & $1027.8[22]$ & $28.9[22]$ & $0.492[22]$ & $0.1790[23]$ \\
\hline Phenol & $692.2[23]$ & $60.5[23]$ & $0.450[23]$ & $0.0890[6]$ \\
\hline 2,5-Xylenol & $706.9[23]$ & $48.0[24]$ & $0.569[24]$ & $0.1257[24]$ \\
\hline 3,4-Xylenol & $729.8[23]$ & $49.0[24]$ & $0.576[24]$ & 0.1243 [24] \\
\hline 1-Hexadecanol & $761.0[20]$ & 14.9 [20] & $0.748[20]$ & $0.2965[22]$ \\
\hline 1-Octadecanol & $777.0[20]$ & 13.4 [20] & $0.863[20]$ & 0.3330 [22] \\
\hline 1-Eicosanol & 792.0 [20] & 12.2 [20] & $0.937[20]$ & 0.3552 [22] \\
\hline Lauric acid & $734.0[20]$ & 19.2 [20] & $0.967[20]$ & $0.2290[25]$ \\
\hline Myristic acid & $756.0[20]$ & $16.8[20]$ & $1.025[20]$ & $0.2575[25]$ \\
\hline Palmitic acid & $776.0[20]$ & 14.9 [20] & $1.083[20]$ & $0.2857[25]$ \\
\hline Stearic acid & $799.0[20]$ & 13.4 [20] & $1.084[20]$ & 0.3024 [22] \\
\hline
\end{tabular}

adjustable parameters in solid solubility calculations. Table 3 lists the solid vapor pressure parameters taken from various literatures where an Antoine type equation is employed. Some of these literature values can only be used in a very small temperature range. Table 4 presents the optimally fitted solid vapor pressure parameters for each pure compound in the volume correction method of this study. Fig. 2 shows the optimally fitted solid vapor pressures of four aromatic compounds. For these compounds, the

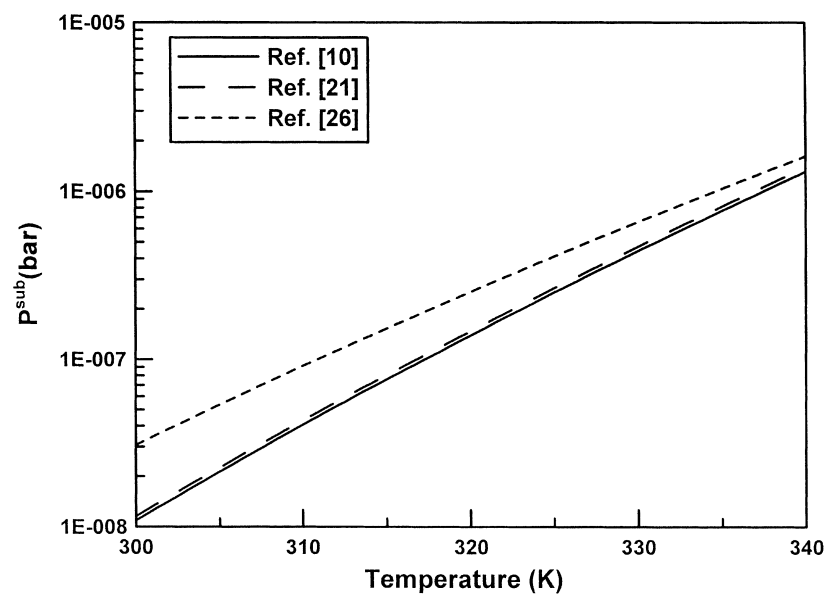

Fig. 1. Sublimation pressure of anthracene from various literature sources. 
Table 3

Antoine constants for solid sublimation vapor pressures from literature ${ }^{\mathrm{a}}$

\begin{tabular}{|c|c|c|c|c|c|}
\hline Compound & A & $\mathrm{B}$ & $\mathrm{C}$ & Pressure unit & Reference \\
\hline \multirow[t]{3}{*}{ Naphthalene } & 11.706 & 2619.9 & 52.5 & $\mathrm{~Pa}$ & [10] \\
\hline & 8.583 & 3733.9 & 0.0 & Bar & [4] \\
\hline & 13.575 & 3729.3 & 0.0 & $\mathrm{~Pa}$ & [5] \\
\hline \multirow[t]{2}{*}{ Phenanthracene } & 13.775 & 4567.7 & 0.0 & $\mathrm{~Pa}$ & [10] \\
\hline & 9.631 & 4873.4 & 0.0 & Bar & [21] \\
\hline \multirow[t]{3}{*}{ Anthracene } & 14.755 & 5313.7 & 0.0 & $\mathrm{~Pa}$ & {$[10]$} \\
\hline & 7.146 & 4397.6 & 0.0 & Bar & {$[21]$} \\
\hline & 9.775 & 5313.7 & 0.0 & Bar & {$[26]$} \\
\hline \multirow[t]{2}{*}{ 2,3-Dimethylnaphthalene } & 13.972 & 4222.3 & 0.0 & $\mathrm{~Pa}$ & {$[10]$} \\
\hline & 9.065 & 4302.5 & 0.0 & Bar & [21] \\
\hline \multirow[t]{2}{*}{ 2,6-Dimethylnaphthalene } & 15.26 & 4683.3 & 0.0 & $\mathrm{~Pa}$ & {$[10]$} \\
\hline & 9.429 & 4419.5 & 0.0 & Bar & [21] \\
\hline Hexamethylbenzene & 13.134 & 3855.0 & 21.0 & $\mathrm{~Pa}$ & [5] \\
\hline Pyrene & 8.395 & 4904.0 & 0.0 & Bar & {$[21]$} \\
\hline Fluorene & 9.429 & 4419.5 & 0.0 & Bar & {$[21]$} \\
\hline Phenol & 13.689 & 3586.4 & 0.0 & $\mathrm{~Pa}$ & [27] \\
\hline 2,5-Xylenol & 15.495 & 4438.6 & 0.0 & $\mathrm{~Pa}$ & [27] \\
\hline 3,4-Xylenol & 15.298 & 4478.2 & 0.0 & $\mathrm{~Pa}$ & [27] \\
\hline 1-Hexadecanol & 22.773 & 8736.0 & 0.0 & $\mathrm{KPa}$ & {$[28]$} \\
\hline 1-Octadecanol & 24.990 & 9787.0 & 0.0 & $\mathrm{KPa}$ & {$[28]$} \\
\hline 1-Eicosanol & 28.860 & 113.93 & 0.0 & $\mathrm{KPa}$ & {$[28]$} \\
\hline Lauric acid & 16.710 & 6683.0 & 0.0 & $\mathrm{KPa}$ & [28] \\
\hline Myristic acid & 6.786 & 2143.4 & 143.27 & $\mathrm{KPa}$ & [28] \\
\hline Palmitic acid & 19.342 & 8069.0 & 0.0 & $\mathrm{KPa}$ & [28] \\
\hline Stearic acid & 6.171 & 2157.5 & 153.78 & $\mathrm{KPa}$ & [28] \\
\hline
\end{tabular}

${ }^{\text {a }}$ The solid sublimation pressures are fitter by $\log P^{\text {sub }}=A-B /(T(\mathrm{~K})-C)$. For triphenylene, the sublimation vapor pressure are [29] $1.11 \times 10^{-5} \mathrm{~Pa}(308 \mathrm{~K}), 4.69 \times 10^{-5} \mathrm{~Pa}(318 \mathrm{~K}), 1.83 \times 10^{-4} \mathrm{~Pa}(328 \mathrm{~K})$. For chrysene, the sublimation vapor pressure is [29] $4.17 \times 10^{-6} \mathrm{~Pa}(308 \mathrm{~K})$.

best-fitted solid vapor pressures increase with temperature, and they are close to the literature data. This result indicates that although the sublimation vapor pressures are taken as adjustable parameters in the solid solubility calculations, their optimally fitted values are reasonable and in good agreement with the available experimental data. It also provides a good basis that we can extend the solid vapor pressure adjustment in the volume correction method to heavy compounds where no exact experimental vapor pressure data are available.

In this study, the solubilities of non-polar and polar solids in supercritical carbon dioxide are calculated using a group contribution mixing rule with a volume correction term. The optimally fitted parameters in the volume correction term for various solid compounds are shown in Table 5. The calculated results of the solubilities of non-polar aromatic compounds in supercritical carbon dioxide are shown in Table 6 . The absolute average deviations (AAD) of the solid solubility from different mixing rules are compared in this table. For the traditional van der Waals mixing rules with single or dual binary interaction parameters and their optimally fitted solid vapor pressures, the AADs are 7.52 and $6.24 \%$, respectively. The group contribution mixing rules with the optimally fitted $K_{1}$ and $K_{2}$ volume correction parameters give a 
Table 4

Optimally fitted Antoine constants of solid vapor pressures in this study ${ }^{\mathrm{a}}$

\begin{tabular}{llr}
\hline Compound & A & B \\
\hline Naphthalene & 14.674 & 4069.694 \\
Phenanthracene & 15.690 & 5174.050 \\
Anthracene & 15.019 & 5406.851 \\
2,3-Dimethylnaphthalene & 14.066 & 4265.729 \\
2,6-Dimethylnaphthalene & 15.260 & 4683.320 \\
Hexamethylbenzene & 13.462 & 4229.699 \\
Pyrene & 14.786 & 5421.404 \\
Fluorene & 14.276 & 4583.529 \\
Triphenylene & 14.462 & 5804.057 \\
Myristic acid & 22.113 & 7805.443 \\
Palmitic acid & 31.154 & 10860.70 \\
Benzoic acid & 16.980 & 5865.607 \\
\hline
\end{tabular}

${ }^{a}$ The solid sublimation pressures are fitted by $\log P^{\mathrm{sub}}(\mathrm{Pa})=A-B / T(\mathrm{~K})$. For other compounds, at $308 \mathrm{~K}: P^{\text {sub }}$ (chrysene): $9.448 \times 10^{-11}$ bar; $P^{\text {sub }}$ (3,4-xylenol): $4.327 \times 10^{-5}$ bar; $P^{\text {sub }}\left(2,5\right.$-xylenol): $1.201 \times 10^{-4}$ bar; $P^{\text {sub }}(1$-hexadecaonol): $1.960 \times$ $10^{-6}$ bar; $P^{\text {sub }}\left(1\right.$-octadecanol): $1.366 \times 10^{-6}$ bar; $P^{\text {sub }}\left(1\right.$-eicosanol): $6.447 \times 10^{-7}$ bar; $P^{\text {sub }}$ (stearic acid): $1.644 \times 10^{-10}$ bar; at $309 \mathrm{~K}: P^{\text {sub }}$ (phenol): $1.411 \times 10^{-3}$ bar; at $313 \mathrm{~K}: P^{\text {sub }}$ (lauric acid): $7.033 \times 10^{-8}$ bar.

comparable AAD of $6.20 \%$. The $K_{1}$ and $K_{2}$ values for non-polar fluids are correlated as functions of the solid molar volume in this study:

$$
\begin{aligned}
& K_{1}=0.00311+0.0839 V_{\mathrm{s}} \\
& K_{2}=-16.1959+296.6818 V_{\mathrm{s}}-1370.0698 V_{\mathrm{s}}^{2}
\end{aligned}
$$

where $V_{\mathrm{s}}$ is the solid molar volume $(1 / \mathrm{mol})$. If the generalized $K_{1}$ and $K_{2}$ correlation equations are employed, an AAD of $6.98 \%$ is obtained. In using the generalized correlation equations of sublimation vapor pressures and the volume correction parameters, there is no individually adjustable factor in the

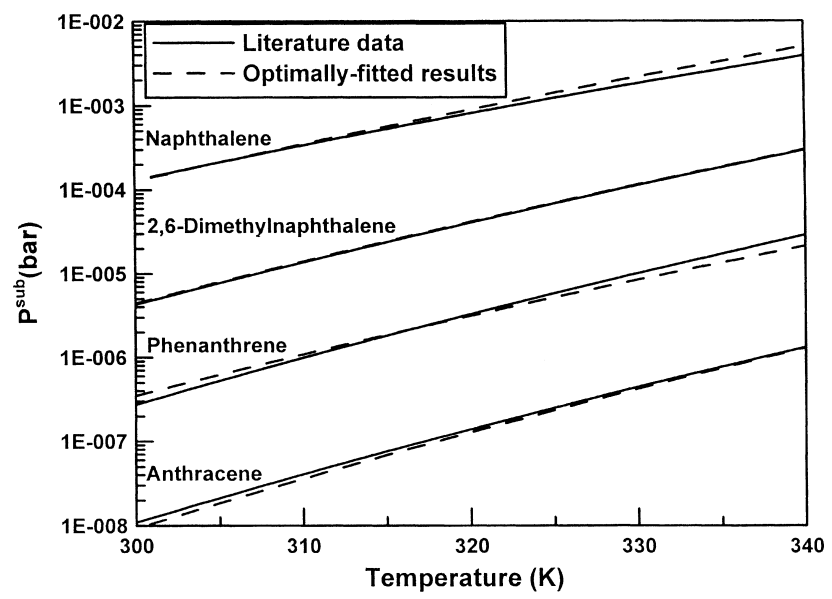

Fig. 2. Comparison of the optimally-fitted sublimation pressures of various solids with literature data. 
Table 5

Optimally-fitted $K_{1}$ and $K_{2}$ values in this study

\begin{tabular}{lrr}
\hline Compound & $K_{1}$ & $K_{2}$ \\
\hline Naphthalene & 0.0127 & -0.1024 \\
Phenanthracene & 0.0154 & -2.6165 \\
Anthracene & 0.0146 & -2.1497 \\
2,3-Dimethylnaphthalene & 0.0162 & -3.2499 \\
2,6-Dimethylnaphthalene & 0.0141 & -1.4620 \\
Hexamethylbenzene & 0.0159 & -2.8341 \\
Pyrene & 0.0165 & -3.6783 \\
Fluorene & 0.0148 & -1.4536 \\
Triphenylene & 0.0178 & -6.2350 \\
Chrysene & 0.0182 & -6.9883 \\
Phenol & 0.0357 & -1.5750 \\
2,5-Xylenol & 0.0622 & -2.6610 \\
3,4-Xylenol & 0.0583 & -2.5407 \\
1-Hexadecanol & -0.0694 & -0.0947 \\
1-Octadecanol & -0.1192 & 1.3682 \\
1-Eicosanol & -0.1913 & 2.4482 \\
Lauric acid & 0.0434 & -2.2683 \\
Myristic acid & 0.0402 & -2.6667 \\
Palmitic acid & 0.0149 & -0.6472 \\
Stearic acid & -0.0506 & 0.2354 \\
\hline
\end{tabular}

solid solubility calculations. The calculation results are satisfactory, and are comparable to those from the VDW mixing models with optimally fitted binary parameters. Fig. 3 shows the correlation results of the volume correction parameters for non-polar systems. It is demonstrated that both $K_{1}$ and $K_{2}$ parameters are well correlated as functions of the solid molar volumes. Fig. 4 shows the comparison of our calculated results with the experimental data for fluorine in supercritical carbon dioxide. The generalized correlation equations of the solid vapor pressure and the volume correction term are used. The calculated results yield good agreement with experimental data at different temperatures. Another comparison is shown in Fig. 5 for the solid solubility of triphenylene in supercritical carbon dioxide. The agreement with experimental data is again satisfactory where only generalized parameters are used in the solubility calculations. The satisfactory correlation of $K_{1}$ and $K_{2}$ as functions of pure solid molar volumes also indicates that the volume correction method can be used to predict the solid solubility in supercritical carbon dioxide.

The calculated results for the solid solubility of polar compounds are shown in Table 7. It is indicated that the traditional van der Waals mixing rules with dual binary parameters, and the group contribution mixing model with optimally fitted volume correction parameters give satisfactory results where the AAD is less than $6 \%$. The volume correction term parameters for polar compounds are also correlated as functions of the solid molar volume in this study:

$$
\begin{aligned}
& K_{1}=-0.18057+3.0725 V_{\mathrm{s}}-8.6651 V_{\mathrm{s}}^{2} \\
& K_{2}=2.85074-66.703 V_{\mathrm{s}}+185.54 V_{\mathrm{s}}^{2}
\end{aligned}
$$

Using these generalized volume correction parameters, an AAD of $12.76 \%$ for the solid solubility calculations is obtained. This result is comparable to that from the traditional van der Waals mixing model with 
Table 6

Calculation results of non-polar aromatic solid solubilities in supercritical carbon dioxide

\begin{tabular}{|c|c|c|c|c|c|c|c|c|}
\hline \multirow{3}{*}{$\begin{array}{l}\text { Solid } \\
\text { (compound 2) }\end{array}$} & \multirow{3}{*}{$\begin{array}{l}\text { Number of } \\
\text { data points }\end{array}$} & \multirow{3}{*}{$\begin{array}{l}\text { Temperature } \\
\text { range }(\mathrm{K})\end{array}$} & \multirow{3}{*}{$\begin{array}{l}\text { Press range } \\
(\mathrm{MPa})\end{array}$} & \multicolumn{4}{|c|}{$\mathrm{AADY}_{2}(\%)^{\mathrm{a}}$} & \multirow{3}{*}{$\begin{array}{l}\text { Data } \\
\text { reference }\end{array}$} \\
\hline & & & & \multicolumn{2}{|c|}{ VDW mixing rules } & \multicolumn{2}{|l|}{ This work } & \\
\hline & & & & $\begin{array}{l}\text { Optimally- } \\
\text { fitted } k_{12}\end{array}$ & $\begin{array}{l}\text { Optimally-fitted } \\
k_{12} \text { and } l_{12}\end{array}$ & $\begin{array}{l}\text { Optimally-fitted } \\
K_{1} \text { and } K_{2} \\
\end{array}$ & $\begin{array}{l}\text { Generalized } \\
K_{1} \text { and } K_{2} \\
\end{array}$ & \\
\hline Naphthalene & 44 & $308-333$ & $8-29$ & 16.76 & 5.71 & 6.86 & 6.84 & {$[30]$} \\
\hline Phenanthracene & 15 & $318-338$ & $12-28$ & 4.17 & 3.70 & 4.54 & 9.83 & {$[31]$} \\
\hline Anthracene & 20 & $303-343$ & $10-41$ & 4.31 & 4.31 & 7.92 & 9.29 & {$[5]$} \\
\hline 2,3-Dimethylnaphthalene & 14 & $308-328$ & $10-28$ & 5.19 & 5.16 & 4.61 & 12.86 & {$[31]$} \\
\hline 2,6-Dimethylnaphthalene & 15 & $308-328$ & $10-28$ & 5.56 & 5.56 & 3.96 & 4.86 & {$[31]$} \\
\hline Hexamethylbenzene & 24 & $303-343$ & $7-48$ & 10.72 & 9.94 & 9.51 & 11.44 & [5] \\
\hline Pyrene & 120 & $308-328$ & $8-25$ & 6.87 & 6.72 & 5.99 & 6.01 & {$[32]$} \\
\hline Fluorene & 130 & $308-328$ & $7-25$ & 6.70 & 6.70 & 6.24 & 6.54 & {$[32]$} \\
\hline Triphenylene & 28 & $308-328$ & $8-25$ & 4.88 & 4.76 & 5.34 & 5.41 & [29] \\
\hline Chrysene & 11 & 308 & $8-25$ & 3.18 & 2.78 & 4.60 & 4.77 & [29] \\
\hline Total & 421 & & & 7.52 & 6.24 & 6.20 & 6.98 & \\
\hline
\end{tabular}

${ }^{\mathrm{a}} \mathrm{AADY}_{2}(\%)=(100 / \mathrm{NP}) \sum_{i}\left|\left(y_{2, i}^{\mathrm{cal}}-y_{2, i}^{\exp }\right) / y_{2, i}^{\exp }\right| ; \mathrm{NP}$ : number of data point. 


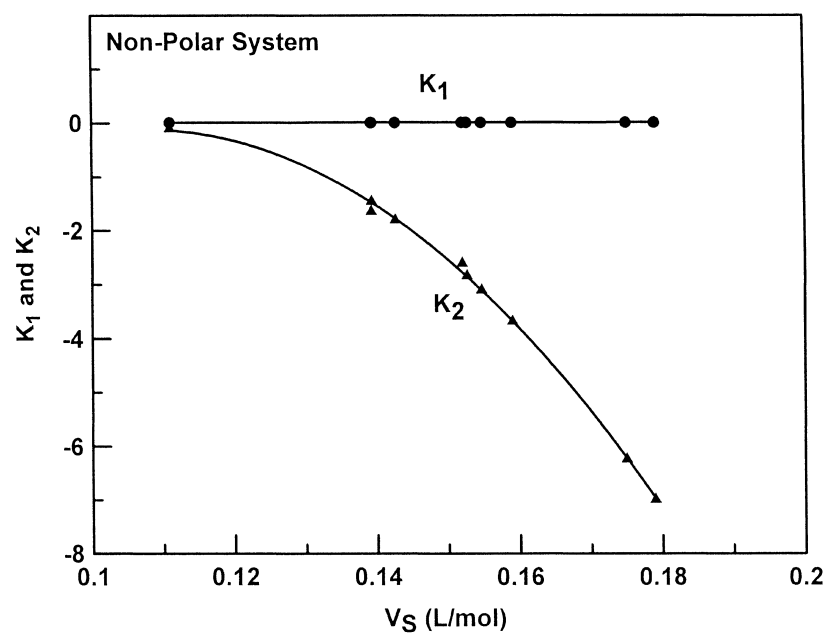

Fig. 3. Correlation of the volume correction parameters for non-polar solid compounds.

one optimally fitted binary energy parameter. The group contribution mixing rules with the generalized volume correction parameters suggest an acceptable method for the estimation of heavy solid solubilities in supercritical carbon dioxide. Fig. 6 shows the correlation results of the volume correction parameters for the polar compounds. The solid molar volume covers a wider range over $0.35 \mathrm{l} / \mathrm{mol}$. The calculated results using the generalized volume correction model for the solid solubility of three heavy alcohol compounds are shown in Fig. 7. Fig. 8 presents those calculated results of heavy acid compounds. It is observed that the agreement with experimental data is satisfactory. The group contribution mixing model with generalized volume correction parameters also gives better results than those from the solution model presented by Iwai et al. [38]. In the latter solution model, an AAD over $20 \%$ is observed with two individually adjusted parameters.

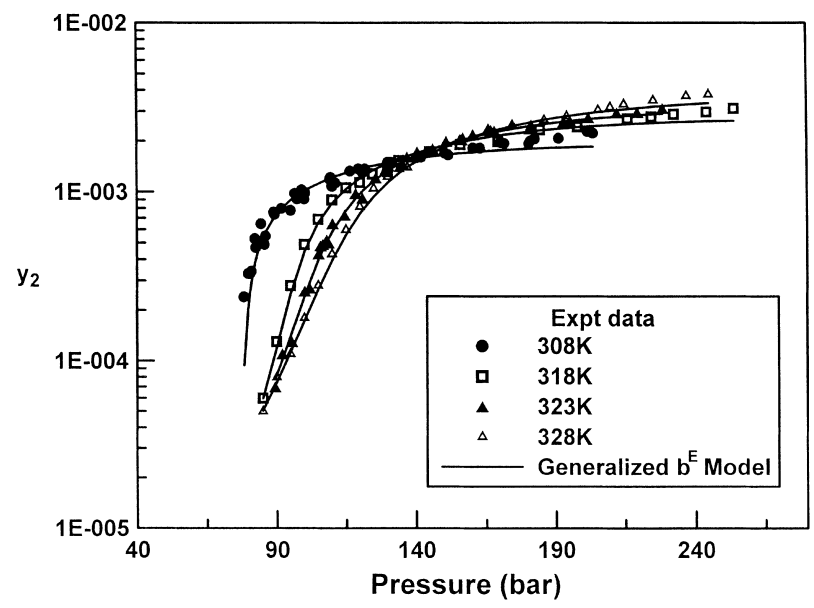

Fig. 4. Calculation results for the solid solubility of fluorene in supercritical carbon dioxide with a generalized volume correction method. 


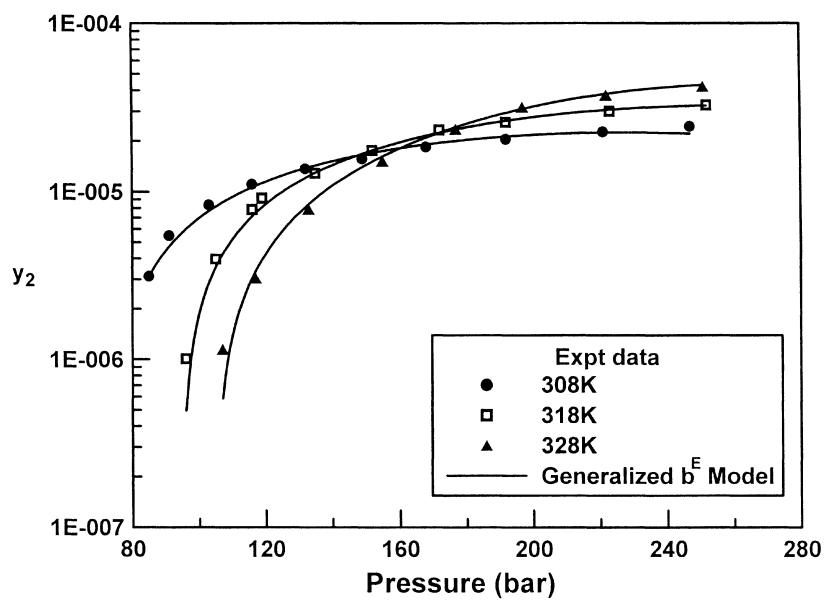

Fig. 5. Calculation results for the solid solubility of triphenylene in supercritical carbon dioxide with a generalized volume correlation term.

Further application of the EOS + UNIFAC method with a generalized volume correction term is extended to predict the solid solubilities of ternary systems with two solids. For the ternary system, we have shown that the volume correction term was written as [14]:

$$
b^{\mathrm{E}}=x_{1} x_{2}\left(K_{1} x_{1}+K_{2} x_{2}\right)+x_{1} x_{3}\left(K_{1} x_{1}+K_{3} x_{3}\right)
$$

where the subscript 1 represents the solvent of carbon dioxide, subscripts 2 and 3 represent the two solid components. No interaction of the solid components is assumed in this model. The values of the $K$ factors

Table 7

Calculation results of polar solid solubilities in supercritical carbon dioxide

\begin{tabular}{|c|c|c|c|c|c|c|c|c|}
\hline \multirow{3}{*}{$\begin{array}{l}\text { Solid } \\
\text { (compound 2) }\end{array}$} & \multirow{3}{*}{$\begin{array}{l}\text { Number } \\
\text { of data } \\
\text { points }\end{array}$} & \multirow{3}{*}{$\begin{array}{l}\text { Temperature } \\
\text { range }(\mathrm{K})\end{array}$} & \multirow{3}{*}{$\begin{array}{l}\text { Press } \\
\text { range } \\
(\mathrm{MPa})\end{array}$} & \multicolumn{4}{|c|}{$\mathrm{AADY}_{2}(\%)^{\mathrm{a}}$} & \multirow{3}{*}{$\begin{array}{l}\text { Data } \\
\text { - reference }\end{array}$} \\
\hline & & & & \multicolumn{2}{|c|}{ VDW mixing rules } & \multicolumn{2}{|l|}{ This work } & \\
\hline & & & & $\begin{array}{l}\text { Optimally- } \\
\text { fitted } k_{12}\end{array}$ & $\begin{array}{l}\text { Optimally-fitted } \\
k_{12} \text { and } l_{12}\end{array}$ & $\begin{array}{l}\text { Optimally-fitted } \\
K_{1} \text { and } K_{2}\end{array}$ & $\begin{array}{l}\text { Generalized } \\
K_{1} \text { and } K_{2} \\
\end{array}$ & \\
\hline Phenol & 25 & 309 & $8-25$ & 17.95 & 3.98 & 7.20 & 18.44 & [33] \\
\hline 3,4-Xylenol & 7 & 308 & $8-26$ & 16.29 & 2.41 & 1.24 & 2.57 & [34] \\
\hline 2,5-Xylenol & 8 & 308 & $7-27$ & 19.22 & 3.82 & 2.22 & 3.81 & [35] \\
\hline 1-Hexadecanol & 6 & 308 & $8-22$ & 5.56 & 3.99 & 1.52 & 12.99 & [36] \\
\hline 1-Octanol & 9 & 308 & $9-24$ & 3.12 & 2.33 & 6.76 & 8.09 & [37] \\
\hline 1-Eicosanol & 7 & 308 & $8-24$ & 9.66 & 5.80 & 7.25 & 7.25 & {$[37]$} \\
\hline Lauric acid & 8 & 313 & $8-25$ & 15.91 & 8.01 & 3.46 & 19.24 & [25] \\
\hline Myristic acid & 13 & $308-313$ & $8-23$ & 13.66 & 11.24 & 12.11 & 25.40 & {$[25,36]$} \\
\hline Palmitic acid & 13 & $308-313$ & $9-23$ & 4.75 & 4.74 & 5.00 & 7.38 & {$[25,36]$} \\
\hline Stearic acid & 8 & 308 & $9-24$ & 6.71 & 3.89 & 4.49 & 4.54 & [37] \\
\hline Total & 104 & & & 12.17 & 5.15 & 5.99 & 12.76 & \\
\hline
\end{tabular}

\footnotetext{
${ }^{\mathrm{a}} \mathrm{AADY}_{2}(\%)=\left(100 / \mathrm{NP} \sum_{i}\left|\left(y_{2, i}^{\mathrm{cal}}-y_{2, i}^{\exp }\right) / y_{2, i}^{\exp }\right| ; \mathrm{NP}\right.$ : number of data point.
} 


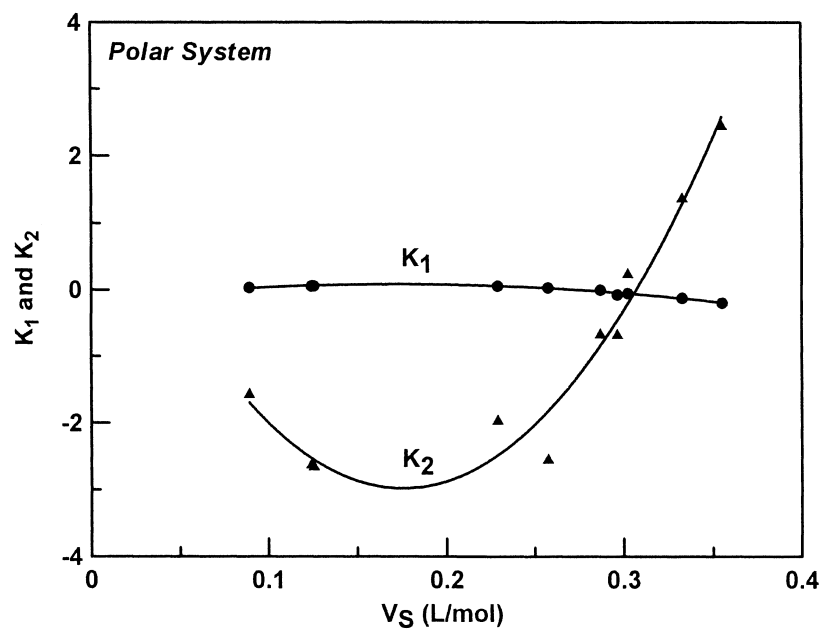

Fig. 6. Correlation of the volume correction parameters for polar solid compounds.

are expressed by Eqs. (21) to (24) for either the non-polar or polar system. In this case, the ternary system calculations are completely predictive where only generalized binary system parameters are employed. Table 8 shows our calculated results for the solid solubilities in the ternary mixtures. Generally, the predictions are satisfactory where the grand AAD value is less than $10 \%$. It is observed from Table 8 that not only good prediction can be obtained in non-polar mixtures, the prediction results are also satisfactory for the asymmetric mixtures of polar and non-polar solids such as benzoic acid with naphthalene or phenanthrene. In Table 8 we also compare our calculation results using the volume correction method with those from other methods in literature. The results of Balbuena et al. [42] are calculated with the lattice model. The method employed by Garnier et al. [43] is the modified Peng-Robinson EOS with van der Waals mixing rules. The lattice model approach [42] requires one ternary parameter, and the methods of Garnier et al. [43] and this work directly predict the ternary solubility using binary

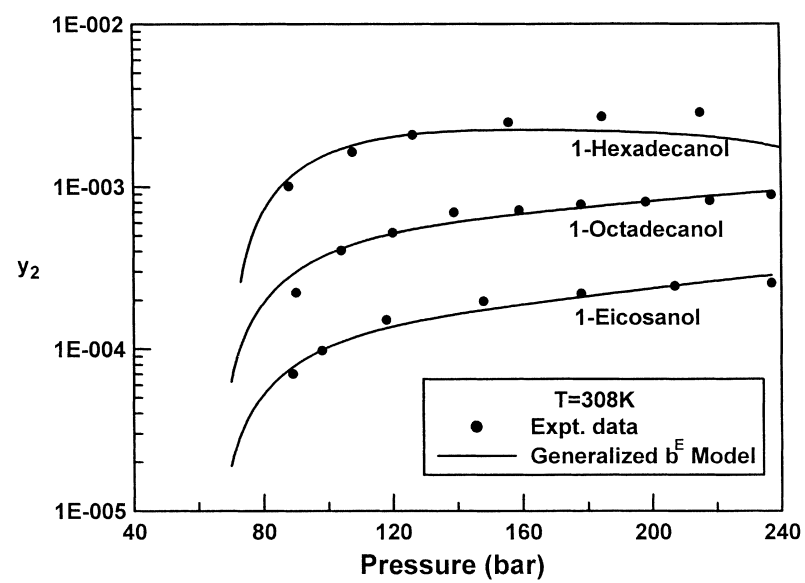

Fig. 7. Calculation results for the solid solubilities of various heavy alcohols in supercritical carbon dioxide. 
Table 8

Calculation results on ternary systems with two solids in supercritical carbon dioxide ${ }^{\mathrm{a}}$

\begin{tabular}{|c|c|c|c|c|c|c|c|c|c|c|c|}
\hline \multirow{2}{*}{$\begin{array}{l}\text { Solid } \\
\text { (compound 2) }\end{array}$} & \multirow{2}{*}{$\begin{array}{l}\text { Solid } \\
\text { (compound 3) }\end{array}$} & \multirow{2}{*}{$\begin{array}{l}\text { Number } \\
\text { of data } \\
\text { points }\end{array}$} & \multirow{2}{*}{$\begin{array}{l}\text { Temperature } \\
\text { range }(\mathrm{K})\end{array}$} & \multirow{2}{*}{$\begin{array}{l}\text { Pressure } \\
\text { range } \\
\text { (Mpa) }\end{array}$} & \multicolumn{2}{|c|}{ Balbuena et al. [42] } & \multicolumn{2}{|c|}{ Garnier et al. [43] } & \multicolumn{2}{|c|}{ This work } & \multirow{2}{*}{$\begin{array}{l}\text { Data } \\
\text { reference }\end{array}$} \\
\hline & & & & & $\begin{array}{l}\text { AADY } \\
(\%)\end{array}$ & $\begin{array}{l}2 \mathrm{AADY}_{3} \\
(\%)\end{array}$ & $\begin{array}{l}\text { AADY } \\
(\%)\end{array}$ & $\begin{array}{l}\mathrm{AADY}_{3} \\
(\%)\end{array}$ & $\begin{array}{l}\text { AADY } \\
(\%)\end{array}$ & $\begin{array}{l}\mathrm{AADY}_{3} \\
(\%)\end{array}$ & \\
\hline Phenanthrene & Anthrance & 10 & $308-318$ & $10-24$ & NA & NA & 28.94 & 11.70 & 14.90 & 10.19 & [39] \\
\hline Phenanthrene & 2,6-Dimethylnaphthalene & 5 & 308 & $12-28$ & NA & NA & 20.12 & 17.39 & 5.20 & 4.77 & [3] \\
\hline Naphthalene & 2,3-Dimethylnaphthalene & 5 & 308 & $12-28$ & 10.41 & 6.31 & NA & NA & 21.15 & 19.47 & [3] \\
\hline 2,3-Dimethylnaphthalene & 2,6-Dimethylnaphthalene & 18 & $308-318$ & $12-28$ & NA & NA & 15.14 & 21.48 & 8.34 & 5.74 & {$[3]$} \\
\hline Phenanthrene & Nap hthalene & 18 & 308 & $12-28$ & 22.91 & 9.45 & 20.04 & 15.52 & 12.72 & 12.27 & [3] \\
\hline 2-Naphthol & Phenanthrene & 16 & $308-328$ & $13-34$ & NA & NA & NA & NA & 15.91 & 11.81 & [40] \\
\hline 2-Naphthol & Anthrance & 6 & 308 & $12-35$ & NA & NA & NA & NA & 6.85 & 10.86 & [41] \\
\hline Benzoic acid & Naphthalene & 10 & $308-318$ & $12-28$ & 30.72 & 32.14 & NA & NA & 17.05 & 6.78 & [3] \\
\hline Benzoic acid & Phenanthrene & 5 & 308 & $12-28$ & NA & NA & NA & NA & 19.77 & 5.02 & [3] \\
\hline
\end{tabular}

${ }^{\mathrm{a}} \mathrm{AADY}_{2}(\%)=\left(100 / \mathrm{NP} \sum_{i}\left|\left(y_{2, i}^{\text {cal }}-y_{2, i}^{\exp }\right) / y_{2, i}^{\exp }\right| ; \mathrm{AADY}_{3}(\%)=\left(100 / \mathrm{NP} \sum_{i}\left|\left(y_{3, i}^{\mathrm{cal}}-y_{3, i}^{\exp }\right) / y_{3, i}^{\exp }\right| ; \mathrm{NP}\right.\right.$ : number of data point; NA: not available. 


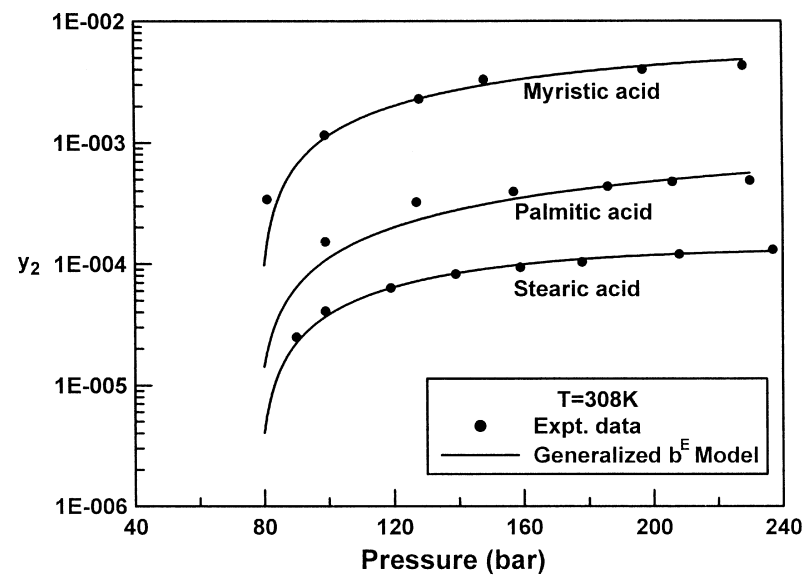

Fig. 8. Calculation results for the solid solubilities for various fatty acids in supercritical carbon dioxide.

parameters. It is demonstrated that the volume correction method of this work yields an overall smaller AAD in solid solubilities. Graphical presentations of our calculation results for ternary systems are shown in Figs. 9 and 10, respectively. Our predicted results are in close agreement to the experimental data. The EOS + UNIFAC method with generalized volume correction term is applicable in binary and ternary systems. The generalized correlation of the volume correction term is extended to a wider range in this study that enables the EOS + UNIFAC method to calculate the solubilities of heavy polar solids in supercritical carbon dioxide with satisfactory results.

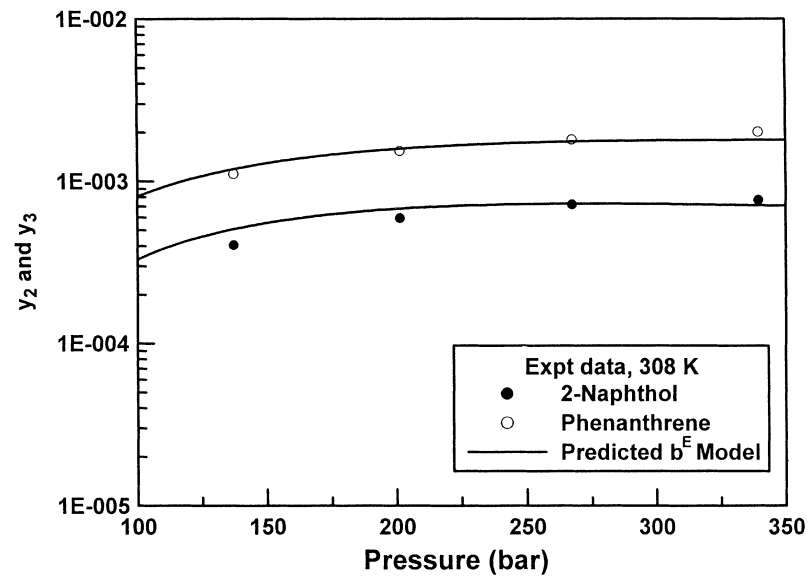

Fig. 9. Predicted solubilities of 2-naphthol (2) and phenanthrene (3) in $\mathrm{CO}_{2}$ (1) 2-naphthol (2) phenanthrene (3) ternary system (for experimental data refer [40]). 


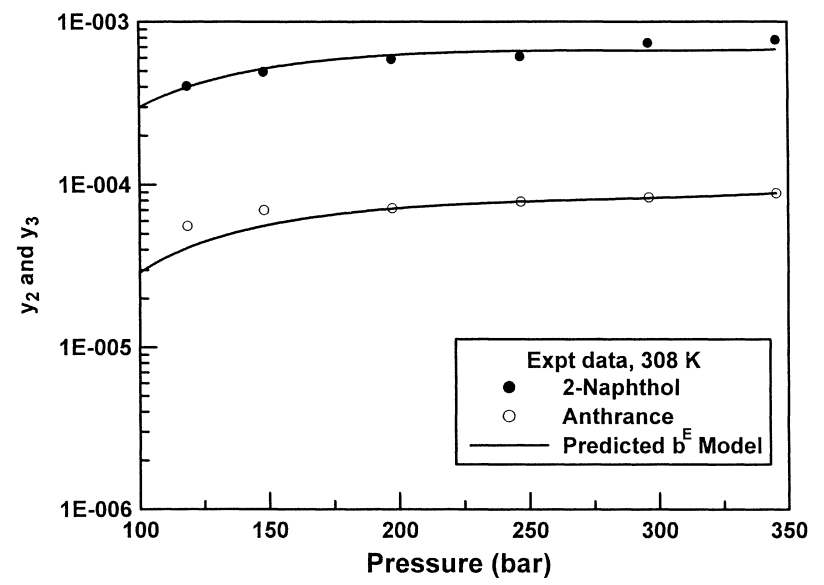

Fig. 10. Predicted solubilities of 2-naphthol (2) and anthrance (3) in $\mathrm{CO}_{2}$ (1) 2-naphthol (2) anthrance (3) ternary system (for experimental data refer [41]).

\section{Conclusion}

A modified Huron-Vidal type mixing model with a volume correction term is employed in calculating the solubilities of heavy compounds in supercritical carbon dioxide. The vapor pressures of heavy solids are taken as adjustable parameters, and the best-fitted values of some compounds are reasonably correlated by a generalized Antoine type equation. The volume correction term parameters are correlated in a wider range of the solid molar volumes for both non-polar and polar systems in this study. The calculated results of the solid solubilities in supercritical carbon dioxide are satisfactory. With the generalized calculation method, the accuracy in solid solubility calculations is comparable to that from the traditional van der Waals mixing model with optimally fitted binary parameters. Our calculation results are also better than those from the solution model approach presented by previous investigations. The mixing model is used to predict the solid solubilities in ternary systems with two solid components. Our calculation results are satisfactory for both the non-polar systems and asymmetric mixtures of polar and non-polar solid mixtures.

\section{List of symbols}

A Helmholtz free energy

$a, b$ parameters of the Peng-Robinson equation of state

$K \quad$ constant in the volume correction term

$k, l \quad$ binary interaction parameters

$n \quad$ number of moles

$P \quad$ pressure

$Q_{v} \quad$ parameter defined Eq. (13)

$q, r$ surface area and volume parameters in the UNIFAC model, respectively.

$R \quad$ gas constant

$T$ temperature 
y solubility

V volume

Greek symbols

$\gamma \quad$ activity coefficient

$\phi \quad$ fugacity coefficient

\section{Superscripts}

E excess property or the volume correction term

SCF supercritical phase

s solid phase

sub sublimation property

Subscripts

$i, j \quad$ component $i, j$

$m$ mixture property

1,2, 3 components $1,2,3$

\section{Acknowledgements}

The authors are grateful to the National Science Council for supporting this research.

\section{References}

[1] G. Anitescu, L.L. Tavlarides, J. Supercritical Fluids 10 (1997) 175-189.

[2] E. Neau, S. Garnier, P. Alessi, A. Cortesi, I. Kikic, High Pressure Chemical Engineering, Elsevier, Amsterdam, 1996, pp. 265-270.

[3] R.T. Kurnik, R.C. Reid, Fluid Phase Equilib. 8 (1982) 93-105.

[4] W.J. Schmitt, R.C. Reid, J. Chem. Eng. Data 31 (1986) 204-212.

[5] K.P. Johnston, D.H. Ziger, C.A. Eckert, Ind. Eng. Chem. Fundam. 21 (1982) 191-197.

[6] M. Mukhopadhyay, G.V.R. Rao, Ind. Eng. Chem. Res. 32 (1993) 922-930.

[7] I. Reiss, A. Schleussinger, S. Schulz, C. Berti, Fluid Phase Equilib. 131 (1997) 37-49.

[8] J.S. Haselow, S.J. Han, R.A. Greenkorn, K.C. Chao, ACS Symposium Series 300, American Chemical Society, Washington, DC, 1986, pp. 156-178.

[9] M.J. Huron, J. Vidal, Fluid Phase Equilib. 3 (1979) 255-271.

[10] Y.J. Sheng, P.C. Chen, Y.P. Chen, D.S.H. Wong, Ind. Eng. Chem. Res. 31 (1992) 967-973.

[11] N.C. Patel, A.S. Teja, Chem. Eng. Sci. 37 (1982) 463-473.

[12] P.C. Chen, Y.P. Chen, D.S.H. Wong, Fluid Phase Equilib. 83 (1993) 175-182.

[13] P.C. Chen, M. Tang, Y.P. Chen, Separation Technology, Elsevier, Amsterdam, 1994, pp. 49-58.

[14] P.C. Chen, M. Tang, Y.P. Chen, Ind. Eng. Chem. Res. 34 (1995) 332-339.

[15] C. Zhong, H. Masuoka, Fluid Phase Equilib. 141 (1997) 13-23.

[16] E. Reverchon, G. Della Porta, R. Taddeo, P. Pallado, A. Stassi, Ind. Eng. Chem. Res. 34 (1995) 4087-4091.

[17] D.Y. Peng, D.B. Robinson, Ind. Eng. Chem. Fundam. 15 (1976) 59-64.

[18] B.L. Larsen, P. Rasmussen, A. Fredenslund, Ind. Eng. Chem. Res. 26 (1987) 2274-2286.

[19] H.K. Hansen, B. Coto, B. Kuhlmann, IVC-SEP, SEP 9212, Institut for Kemiteknik, Denmarks Tekniske Universitet, 1992. 
[20] T.E. Daubert, R.P. Danner, Data Compilation Tables of Properties of Pure Compounds, AIChE/DIPPR, 1989.

[21] D.H. Ziger, C.A. Eckert, Ind. Eng. Chem. Res. 22 (1983) 582-588.

[22] R.C. Weast (Ed.), CRC Handbook of Chemistry and Physics, 69th Edition, CRC Press, Boca Raton, FL, 1989.

[23] R.C. Reid, J.M. Prausnitz, B.E. Poling, The Properties of Gases and Liquids, 4th Edition, McGraw-Hill, New York, 1987.

[24] Y. Mori, T. Shimizu, Y. Iwai, Y. Arai, J. Chem. Eng. Data 37 (1992) 317-319.

[25] T. Bamberger, J.C. Erickson, C.L. Cooney, J. Chem. Eng. Data 33 (1988) 327-333.

[26] S. Sako, K. Ohgaki, T. Katayama, J. Supercritical Fluids 1 (1988) 1-6.

[27] R.J.L. Andon, D.P. Biddiscombe, J.D. Cox, R. Handley, D. Harrop, E.F.G. Herington, J.F. Martin, J. Chem. Soc. (1960) 5246-5255.

[28] M.S. Richard, M. Stainslaw, Handbook of the Thermodynamics of Organics Compounds, Elsevier, Amsterdam, 1987.

[29] L. Barna, J.M. Blanchard, E. Rauzy, C. Berro, J. Chem. Eng. Data 41 (1996) 1466-1469.

[30] M.A. McHugh, M.E. Paulaitis, J. Chem. Eng. Data 25 (1980) 326-329.

[31] R.T. Kurnik, S.J. Holla, R.C. Reid, J. Chem. Eng. Data 26 (1981) 47-51.

[32] K.D. Bartle, A.A. Clifford, S.A. Jafar, J. Chem. Eng. Data 35 (1990) 355-360.

[33] R.A.V. Leer, M.E. Paulaitis, J. Chem. Eng. Data 25 (1980) 257-259.

[34] Y. Mori, T. Shimizu, Y. Iwai, Y. Arai, J. Chem. Eng. Data 37 (1992) 317-319.

[35] Y. Iwai, H. Yamamoto, Y. Tanaka, Y. Arai, J. Chem. Eng. Data 35 (1990) 174-176.

[36] Y. Iwai, T. Fukuda, Y. Koga, Y. Arai, J. Chem. Eng. Data 36 (1991) 430-432.

[37] Y. Iwai, Y. Koga, H. Maruyama, Y. Arai, J. Chem. Eng. Data 38 (1993) 506-508.

[38] Y. Iwai, Y. Koga, T. Fukuda, Y. Arai, J. Chem. Eng. Data 25 (1992) 757-760.

[39] E. Kosal, G.D. Holder, J. Chem. Eng. Data 32 (1987) 148-150.

[40] R.M. Lemert, K.P. Johnston, Fluid Phase Equilib. 59 (1990) 31-55.

[41] J.M. Dobbs, P. Johnston, Ind. Eng. Chem. Res. 26 (1987) 1476-1482.

[42] P. Balbuena, E. Campanella, L. Gribaudo, Fluid Phase Equilib. 62 (1991) 225-238.

[43] S. Garnier, E. Neau, P. Alessi, A. Cortesi, I. Kikic, Fluid Phase Equilib. 158-160 (1999) 491-500. 